\title{
Rechtfertigung, Rechtsnatur und Disponibilität der Schranken des Urheberrechts
}

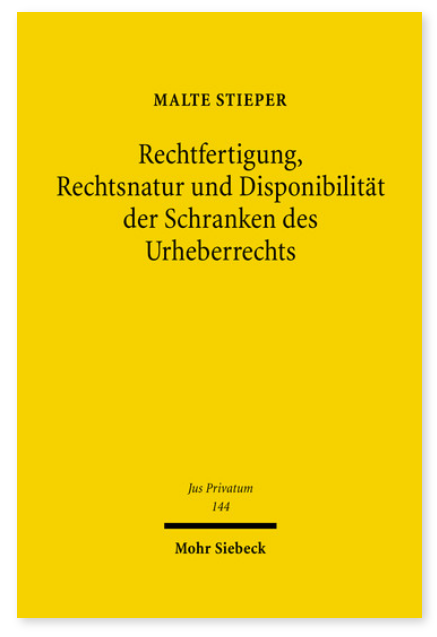

2009. XIX, 584 Seiten. JusPriv 144

ISBN 978-3-16-151221-6

DOI 10.1628/978-3-16-151221-6

eBook PDF 149,00 €

ISBN 978-3-16-150177-7

Leinen $149,00 €$
Das Urheberrecht und seine Schranken sind zwei Seiten derselben Medaille. Das Gleichgewicht zwischen den Verwertungsinteressen der Rechtsinhaber und dem Allgemeininteresse an der Gemeinfreiheit geistiger Güter gerät jedoch zunehmend ins Wanken. Die Möglichkeiten der Digitaltechnik verstärken die Macht der Anbieter, Nutzungsbedingungen durchzusetzen, die den Handlungsspielraum der Nutzer stärker einschränken, als dies der Vorstellung des Gesetzgebers in §§ 44a ff. UrhG entspricht. Nach den philosophischen und verfassungsrechtlichen Grundlagen des Urheberrechts untersucht Malte Stieper, inwieweit solche Einschränkungen der legalen Nutzungsmöglichkeiten zulässig und wirksam sind. Während vertraglichen Beschränkungen durch das Kartellrecht und die AGB-Inhaltskontrolle Grenzen gezogen werden, erweist sich vor allem der Umgehungsschutz technischer Maßnahmen als verfehlt.

Malte Stieper ist Inhaber des Gundling Lehrstuhls für Bürgerliches Recht, Recht des geistigen Eigentums und Wettbewerbsrecht an der Universität Halle-Wittenberg.
Jetzt bestellen:

https://mohrsiebeck.com/buch/rechtfertigung-rechtsnatur-und-disponibilitaet-der-schranken-des-urheberrechts9783161512216?no_cache=1

order@mohrsiebeck.com

Telefon: +49 (0)7071-923-17

Telefax: +49 (0)7071-51104 